\title{
A General Model of Buddhism-Based Management
}

\author{
Hideki Takei \\ Dept. of Information Technology \& Administrative Management, Central Washington \\ University \\ 400 E University Way, Ellensburg, WA, USA \\ E-mail: takeih@cwu.edu
}

Received: Oct. 5, 2020 Accepted: Nov. 16, 2020 Published: Dec. 3, 2020

doi:10.5296/ijssr.v9i1.17785 URL: http://dx.doi.org/10.5296/ijssr.v9i1.17785

\begin{abstract}
Buddhism-based management has been popular among businesspersons. However, many studies about the business seemed subjective as authors used their values and interpretations of Buddhism (Weerasinghe, Thisera, \& Kumara, 2014; Ashtankar, 2015; Shakya, 2017). We agree with Abe's (2007) conclusion that the absence of a generally accepted Buddhism-based business model is the leading cause. We need a general model. This paper suggests a generally accepted Buddhism-based business model by integrating all aspects of Buddhism-based business from published studies and the Buddha's original teachings. We will then use a Japanese Buddhism-based company, Warehouse TERRADA Co, to verify this model.
\end{abstract}

Keywords: Buddhism, management, management principles, ethics 


\section{Introduction}

Buddhism-based management has been popular among businesspersons. There are many academic articles and professional books about the business. However, many of these publications seemed subjective, as the authors used their values and interpretations of Buddhism (Weerasinghe, Thisera, \& Kumara, 2014; Ashtankar, 2015; Shakya, 2017). One of the causes of this problem is the absence of a generally accepted Buddhism-based business model (Abe, 2007).

Without the generally accepted model, most researches tend to be case studies that analyze the relationship between businesspersons' Buddhist philosophy and their business ways. Such case-by-case studies with subjective criteria will not contribute to showing the essence of Buddhism-based management (Abe, 2007).

This paper will suggest a generally accepted Buddhism-based management model by integrating all aspects of Buddhism-based business from published studies and the Buddha's original teachings. Then, we will verify the model with a Japanese Buddhism-based company, Warehouse TERRADA, as it has been recognized as one of the most authentic Buddhism-based business entities in Japan (Diamond, 2016; Gendai, 2018; TERRADA, 2019).

\section{Buddhism-Based Management}

\subsection{Buddhism and Management}

Buddhism-based management has been popular among businesspersons. There are many academic articles and professional books about the business. However, many of these publications seemed subjective, as the authors used their values and interpretations of Buddhism (Weerasinghe, Thisera, \& Kumara, 2014; Ashtankar, 2015; Shakya, 2017). One of the causes of this problem is the absence of a generally accepted Buddhism-based business model (Abe, 2007).

Without the generally accepted model, most researches tend to be case studies that analyze the relationship between businesspersons' Buddhist philosophy and their business ways. Such case-by-case studies with subjective criteria will not contribute to showing the essence of Buddhism-based management (Abe, 2007).

This paper will suggest a generally accepted Buddhism-based management model by integrating all aspects of Buddhism-based business from published studies and the Buddha's original teachings. Then, we will verify the model with a Japanese Buddhism-based company, Warehouse TERRADA, as it has been recognized as one of the most authentic Buddhism-based business entities in Japan (Diamond, 2016; Gendai, 2018; TERRADA, 2019).

\subsection{Buddha's Management Principles}

Payutto (1994), Guruge (2006), Abe (2009), and Essen (2010) developed the Buddha's four management principles to apply to modern management. According to the principles, 
managers maintain profitability by continuously improving employees' industriousness, mindfulness, human relations, and livelihood.

The principles emphasize employees' livelihood because the Buddha repeatedly suggested managers ensuring employees' right livelihood by offering enough food, clothing, shelters, and medicines. Also, he encouraged managers to give employees appropriate work assignments for better livelihood. He said that appropriate work assignments would allow employees to enjoy work, private, and social life (Payutto, 1994; Guruge, 2006; Abe, 2009; Essen, 2010).

The principles suggest that managers develop "mindful organizations" where employees can enjoy balanced livelihoods, be self-managing, and be self-motivated (Guruge, 2006; Field, 2007; Gardiner, 2012; Mathieu \& Peeters, 2016; Prayukvong, 2017).

\subsection{Buddha's Principles of Managerial Functions}

According to Guruge (2006) and Field (2007), managers can apply Buddha's teachings to managerial functions such as human resource management (HRM), finance, production, and marketing.

According to the Buddha's management principles, HRM's primary function is to ensure employees' right livelihood by giving them appropriate workloads, proper compensations, company-supported health insurance, paid vacations, and leave and time-off (Payutto, 1994; Essen, 2010; Zsolnai, 2013; Mathieu \& Peeters, 2016). Also, HRM should support managers in developing mindfulness in the organization by improving employees' job satisfaction, job enrichment, job security, self-improvement, and self-leadership (Guruge, 2006).

The Buddha supported profit orientation and financial health. He repeatedly emphasized the importance of maintaining sufficient profit to compensate employees, invest for growth, save for the future, and support our societies (Schumacher, 1974; Payutto, 1994; Field, 2007; Essen, 2010; Zsolnai, 2013).

In Buddha's management principles, appropriate profit allocations are equally crucial to healthy profit earning. Managers must allocate profits wisely to bring happiness to a firm, employees, and all stakeholders. Particularly, happiness will come from making a firm secure against misfortunes and continuing philanthropic activities through adequate profit allocations (Schumacher, 1974; Payutto, 1994; Field, 2007; Essen, 2010; Zsolnai, 2013).

While the Buddha supported the profit orientation and financial health, he never endorsed the maximization of profit, business expansion, and organization size. He believed that the extreme directions would create the wrong desire of human beings. Instead of the extreme orientations, he suggested the total profit optimization to maximize all stakeholders' overall well-being, including nature, to prevent the lousy desire (Schumacher, 1974; Payutto, 1994; Field, 2007).

Schumacher (1974) and Hipsher (2011) found products and services management principles in Buddhism. The first principle is that companies must produce products and services to improve incommensurable quality of life, such as health, inner-beauty, and right livelihood. 
The second principle is that cost, human beings, and ecology are equally crucial for healthy products and services policies. The last principle is that products and technology must not eliminate jobs but support workers. Payutto (1994) added one more principle saying that product managers must not encourage consumers' materialism.

Guruge (2006) and Mathieu and Peeters (2016) discussed the Buddha's products and services ideas from the consumers' perspective. According to them, all products and services should give consumers five types of happiness: the happiness of appropriate material comfort, using, being harmless to others and nature, buying, and applying for a long time.

\section{A General Model of Buddhism-Based Management}

\subsection{Elements of a General Model of Buddhism-Based Management}

We have discussed that modern managers could use business essences and principles of the Buddha. In this part, we will discuss factors that a general model of Buddhism-based management must include. Figure 1 summarizes the factors.

First, managers must pay attention to multiple relations between their companies and all stakeholders to make the best possible decision to maximize total welfare. When they make decisions, they must correctly predict the consequences of their choices with a long-term view.

Second, managers must reject extreme orientations in business to make the best possible decisions. Instead, they must honor neutrality to assess business environments objectively without their interests and extreme orientations. They should maintain such neutrality throughout their tenure.

Third, managers must motivate and support employees to be self-leaders, self-learners, and mindful members. Also, managers should continuously improve each employee's industriousness through encouragement, job-rotations, appropriate job assignments, mentoring, attainable expectations, and spiritual advancement opportunities.

Fourth, managers should be mindful of employees' work livelihood. Teamwork, effective conflict management, fair competition, fair treatment, and appropriate compensations would improve the work livelihood. At the same time, managers must be mindful of employees' personal and social livelihood. Especially, giving fair compensation with fringe benefits will make employees' personal and social livelihood satisfactory.

Fifth, managers must pay attention to organization size, work assignments, job enrichment, job satisfaction, compensations with fringe benefits, and employee incentives.

Sixth, managers should allocate profit appropriately for all stakeholders' happiness, protections from misfortunes, and philanthropies.

Finally, managers must offer products that consumers can use them to remove suffering. Notably, high quality, durable, user-friendly, and ecology products will help them remove their suffering. 

A. Know and be mindful of multiple relations between companies and all stakeholders including nature.
B. Know and maintain right interests of companies and all stakeholders including nature to make decisions to maximize welfare of all of them.
C. Predict the long-term impact of the decisions on companies and all stakeholders including nature.
D. Maintain long-term orientation in business planning.
E. Maintain neutrality to correctly assess business environments without extreme interests and preferences.
F. Maintain neutrality throughout a process of decisi on making.
G. Managers as role models, mentors, great motivators, and supporters to encourage employees' self-leadership and confidence.
$\mathrm{H}$. Offer encouragement, job-rotations, appropriate job assignments, mentoring, attainable expectations, and giving opportunities for spiritual advancement to maint ain employees' industriousness.
I Develop mindful organization through teamwork, conflict management, fair competition, fair treatment, and fair compensations.
J. Extend mindfulness to employees' private and social livelihood.
$\mathrm{K}$. Give employees fair compensation which includes not only monetary compensation but also various fringe benefits.
L. Maintain appropriate sizes of organizations and employees to maintain heal thy growth without sacrificing job security.
M. Right work assignments and job enrichment for a higher level of job satisfaction.
N. Allocate profit to make all stakeholders cheerful and happy, protect organizations from misfortunes, and do social contributions and philosophic activities.
O. High quality, long-life, human-friendly, and ecology friendly products and service to support consumers to remove suffering.

Figure 1. Elements of a general model of Buddhism-based management

\subsection{Warehouse TERRADA}

We used Warehouse TERRADA (TERRADA, hereafter) to verify our model because it has been recognized as one of Japan's most authentic Buddhism-based business entities (Diamond, 2016; Gendai, 2018; TERRADA, 2019).

For the past ten years, TERRADA has exclusively focused on super-premium warehouse services for businesses and individuals. Now, TERRADA is a leader in the segment (Diamond, 2016; Gendai, 2018; TERRADA, 2019).

TERRADA has also been famous for the active donation of a significant amount of money to improve community members' livelihood. For example, it donated money to improve social infrastructures, open cafes and restaurants, develop parks, and sponsor cultural and educational events (Diamond, 2016; Gendai, 2018; TERRADA, 2019).

TERRADA CEO Yoshihisa Nakano introduced Buddhism-based management to the firm. Long before becoming a CEO, he had been a philanthropist by donating a significant part of his salaries to educational and artistic events. According to him, he has merely practiced the 
philosophy of Muichibutsu, which means no attachment and desires to anything but the nirvana (Diamond, 2016; Gendai, 2018; TERRADA, 2019).

When he became a CEO, he set two critical managerial goals: to destroy profit-and-growth-focused approaches and create robust stakeholder orientations.

He started downsizing the organization size. In seven years, he reduced 1000 employees to 100 employees and increased per-employee profitability by $800 \%$. Surprisingly, TERRADA has maintained a healthy ten billion-yen level profit every year.

He also started allocating profits with all stakeholders. Notably, he distributed the profits to make philanthropic donations and investments for communities (Diamond, 2016; Gendai, 2018; TERRADA, 2019; Shae, 2019; Goe, 2019).

In several interviews, Mr. Nakano repeatedly said that maximizations of profit, growth, market share, and return on investment were no longer relevant for TERRADA. He also said that the firm would optimize profit, cost, growth, size of operations, and market share to maintain a healthy profit level.

For example, he prohibits investment beyond its financial capacity. He encourages coexistence and co-prosperity with all stakeholders. He offers all employees various opportunities to learn the importance and benefits of coexistence and co-prosperity. He made training programs for managers to make the right decisions for coexistence and co-prosperity with all stakeholders (Diamond, 2016; Gendai, 2018; TERRADA, 2019; Shae, 2019; Goe, 2019).

Mr. Nakano introduced participative decision-making for coexistence and co-prosperity with all stakeholders. At TERRADA, all levels of employees could participate in critical decision-making processes. To improve formal and information communications and collaborations in the decision-making processes, he replaced many executive offices with a sizeable wide-open dining room style office (Diamond, 2016; Gendai, 2018; TERRADA, 2019; Shae, 2019; Goe, 2019).

He also introduced participative assessments for the business environment, decision-making, and implementations. Active small group discussions with all employees will determine the business environment. Then, they will jointly figure out problems and find significant causes of the issues. Then, they will immediately look for solutions that will be beneficial for all stakeholders.

Through the participative processes, employees are becoming more professional, analytical, mindful, ethical, and objective to make the best possible decisions. They are also becoming more responsible for the consequences of their choices and actions (Diamond, 2016; Gendai, 2018; TERRADA, 2019; Shae, 2019; Goe, 2019).

It looks like these managerial actions created not only a mindful organization but also industrious employees. Employees encourage, support, mentor, lead, and prize each other in all organizational hierarchies. For example, TERRADA has given an employee a special bonus when colleagues recognize his or her contributions (Diamond, 2016; Gendai, 2018; 
TERRADA, 2019; Shae, 2019; Goe, 2019).

Mr. Nakano even challenged TERRADA's organizational culture. He introduced a culture of mutual respect for better equality and teamwork in the organization. In a sizeable dining-room-style business office, all employees will be able to work respectfully without harassments.

Mr. Nakano himself is not an exception. He works as an employee in the large office. Other employees regularly recognize him as a role model, a great leader, and a mentor.

TERRADA's new organizational culture has maintained healthy competitive environments without damaging employees' industriousness. Jointly and respectfully working together in the large office makes employee's performances more transparent. Therefore, it allows managers to offer employees proper compensations and fringe benefits (Diamond, 2016; Gendai, 2018; TERRADA, 2019; Shae, 2019; Goe, 2019).

TERRADA's premium warehouse services have been mindful of customers by eliminating their problems and adding convenience. For example, the customers have enjoyed so-called worry-free facilities with anti-earthquake structure, weatherproof facilities, fireproof facilities, and ecology-friendly structures. They make social contributions juts by being TERRADA's customers because the worry-free facilities use safe, ecology-friendly materials for humans, ecology, and recycling (Diamond, 2016; Gendai, 2018; TERRADA, 2019; Shae, 2019; Goe, 2019).

In addition to the premium storage services, they have enjoyed additional features such as item classification services, electric item filing services, auction services, and fast delivery services of the auctioned items (Diamond, 2016; Gendai, 2018; TERRADA, 2019; Shae, 2019; Goe, 2019).

\section{Verification of the General Model}

Mr. Nakano has emphasized optimum levels of profit and cost as well as optimum profit allocations. He applied the middle way concept to make the right decisions. He has asked all employees to understand the entire picture of management and have a broader scope of business activities and influences. That is why they can keep the right intentions for the right decisions. According to Mr. Nakano, these are examples of practices of the law of dependent origination.

Mr. Nakano's leadership for transformation has also reflected his practice of the merciful offerings, which are humanitarian actions for all living matters' benefits. He allocates profit appropriately to make financial donations as philanthropies. As a private person, he has practiced the merciful offering through his philanthropic donations of $70 \%$ of his salary.

Based on these facts, his leadership style satisfies B, E, and G of our general model elements in Figure 1.

Mr. Nakano's transformation made TERRADA a Buddhist style organization called a sangha, the smallest unit of the Buddhist community. TERRADA walked away from the profit 
maximization and introduced profit optimization to eliminate unnecessary desire and attachment from employees. The employees' unnecessary desire and attachment will lead TERRADA to wrong decisions with wrong intentions. The Buddha made a sangha free from members' unnecessary desire and attachment for the same reason. As a sangha honored harmony with all stakeholders, TERRADA honors harmony with all stakeholders by focusing on the optimum and long-term relationship with them.

TERRADA's new corporate culture has created mindful employees who can see appropriate relationships with all stakeholders, including nature. The culture also supports employees to be objective and understand the stakeholders' interests for the right decisions for long-term co-prosperity.

Based on these facts, TERRADA's corporate philosophy satisfies elements of A, B, C, D, E, F, and $\mathrm{N}$ of our model.

The downsizing of TERRADA is an application of principles of a sangha. The Buddha split a sangha into two sanghas when a sangha has more than 20 members. According to the Buddha, an appropriate size of a sangha is within a leader's supervising capability. As long as a sangha maintains the size, all members can receive close supervision, teachings, cloths, foods, and shelters. According to Mr. Nakano, he downsized TERRADA to an appropriate size, attaining optimum profitability through active employee participation under close supervision and leadership. The new size has achieved far better per-employee profitability, job satisfaction level, work assignments, and job enrichment.

The Buddha designed a sangha in a way all members could enjoy merciful offerings and self-development through daily practices. Similarly, TERRADA has maintained work environments where all employees can enjoy works and self-development for their life. New hands-on training programs using on-the-job-training, role models, and experiential learning have continually allowed employees to learn through regular work.

Mr. Nakano went beyond a sangha's principles. For example, when TERRADA created a large dining-room style space, all employees gained chances to enjoy jobs and improve their job satisfaction. Participative decision-making allowed them to continuously become mindful of all stakeholders' long-term co-prosperity and responsible for the consequences of their decisions. They could find multiple opportunities to become self-learners and self-leaders through appropriate job assignments and rotations. Fair competition and performance appraisal improved job satisfaction.

Based on these facts, TERRADA's organization satisfies elements of C, D, E, F, G, H, I, J, K, $\mathrm{L}$, and $\mathrm{M}$ of our model.

The Buddha's supervisions and leadership were all about creating good karmas (actions) and eliminating bad karmas. TERRADA's new management methods are about creating the right actions to satisfy customers and all stakeholders, including nature. According to Mr. Nakano, focusing on a niche segment has allowed TERRADA to enhance all stakeholders' satisfaction and be a mindful market leader who creates long-term co-prosperity. Focusing on the niche has also allowed the company to maintain the optimum organization size for optimum levels 
of profit and cost. Of course, long-term job-security and healthy allocations of profits are essential.

TERRADA's "worry-free warehouse" facilities and premium services have removed customers' problems (sufferings) and given them satisfaction. Also, the facilities using ecology and safe materials for humans and the environment do not harm humans and nature. The materials are also recycle-friendly materials to not harm our living environment. In fact, "no harm" has been a significant value of TERRADA's facilities.

TERRADA has used the profit to build social infrastructures such as parks where people can enjoy nature, river embankments where people can enjoy various events, support cultural and art events, and education programs for community members. It has also built cafes and restaurants where not only employees but also community members can enjoy.

Based on these facts, TERRADA's management satisfies elements of A, B, C, D, L, N, and O of our model.

\section{Summary}

We developed and verified our general model of Buddhism-based management. This model includes the essentials of Buddhism-based management. Such essentials include mindfulness to all stakeholders, the maximization of all stakeholders' welfare, adequate mentoring, appropriate employees' work livelihood, proper sizes of organizations and employment, right profit allocations, and products and services to support consumers to remove problems. Our verification allows our model to decide if a management style if Buddhism-based.

\section{Recommendation}

While we verified the model with a TERRADA case, we recommend confirming our model with other cases being considered Buddhism-based.

\section{References}

Abe, D. (2009). Notes on a Buddhist view of business management: Business in bodhisattva practice. $\quad$ Retrieved 2018, from Ryukoku http://opac.ryukoku.ac.jp/webopac/r-ke-rn_049_04_006._?key=ZEJJXH

Ashtankar, O. (2015). Relevance of Buddhism for Business Management. International Journal of Applied Research, 1(13), 17-20.

Diamond. (2016, November 21). CEO tells all employees, "Leave TERRADA in 5 years!" A unique company, TERRADA. Retrieved 2019, from Diamond: https://diamond.jp/articles/-/107914

Essen, J. (2010). Sufficiency Economy and Santi Asoke: Buddhist Economic Ethics for a Just and Sustainable World. Journal of Buddhist Ethics, 17, 70-99.

Field, L. M. (2007). Business and the Buddha. Boston: Wisdom Publications.

Gardiner, B. (2012, April 3). Business Skills and Buddhist Mindfulness. Retrieved 2018, from 
WSJ https://www.wsj.com/articles/SB10001424052702303816504577305820565167202

Gendai. (2018, October 9). Donating all of his income, Not having cars and a house - Strange Life of TERRADA's CEO. Retrieved 2019, from Gendai https://gendai.ismedia.jp/articles/-/57447

Goe. (2019, February 2). TERRADA's CEO, Yoshihisa Nakano, will donate all of his income except for a small portion to live. Retrieved 2019, from goetheweb https://goetheweb.jp/person/slug-naba54276ee8a

Guruge, A. W. (2006). Buddhist economics - myth and reality. Hsi Lai Journal of Humanistic Buddhism, 7, 71-129.

Hipsher, S. A. (2011). The Impact of Therevada Buddhist Values on Work Practices in Southeast Asia. SIU Journal of Management, 1(1), 76-100.

Matthieu, R., \& Peeters, F. (2016, June 3). Managing Mindfully-Buddhism and Business-Owner. $\quad$ Retrieved 2018, from DOCURI https://docuri.com/download/managing-mindfully-buddhism-and-business-owner_59ae4a4cf 581710a6201ac8f_pdf

Payutto, P. (1994, July). Buddhist Economics: A Middle Way for the Market Place. Retrieved 2018, from Urbandharma https://www.urbandharma.org/pdf/Buddhist_Economics.pdf

Prayukvong, W. (2005). A Buddhist economic approach to the development of community enterprises: A case study from Southern Thailand. Cambridge Journal of Economics, 29, 1171-1185. https://doi.org/10.1093/cje/bei071

Puntasen, A. (2004). Buddhist Economics: Evolution, Theories and its Application to Various Economic Subjects. Bangkok: Amarin Press.

Schumacher, E. (1973). Small is Beautiful. London: Blond and Briggs.

Shae. (2019). TERRADA's CEO, Yoshihisa Nakanno, is a minimalist and single. His honorable life as a Philanthropist. Retrieved 2019, from shae-bear http://shae-bear.com/archives/4255

Shakya, A. (2017, October 8). Buddha in Business Management. Retrieved 2018, from New Business Age https://www.newbusinessage.com/MagazineArticles/view/1927

TERRADA, W. (2019). Terrada's Philosophy. Retrieved 2019, from TERRADA https://www.terrada.co.jp/ja

Weerasinghe, T., Thisera, T., \& Kumara, R. (2014). Buddhism and Organizational Management: A Review. Kelaniya Journal of Management, 3(2), 93-112. https://doi.org/10.4038/kjm.v3i2.7484

Zsolnai, L. (2013). Buddhist Economics for Business. Retrieved 2018, from laszlo-zsolnai http://laszlo-zsolnai.net/sites/default/files/3/documents/Buddhist $\% 20$ Economics $\% 20$ for $\% 20 \mathrm{~B}$ usiness $\% 20$ corrected.pdf 


\section{Copyrights}

Copyright for this article is retained by the author(s), with first publication rights granted to the journal.

This is an open-access article distributed under the terms and conditions of the Creative Commons Attribution license (http://creativecommons.org/licenses/by/4.0/). 